\title{
Reclassification of Streptomyces caeruleus as a synonym of Actinoalloteichus cyanogriseus and reclassification of Streptomyces spheroides and Streptomyces laceyi as later synonyms of Streptomyces niveus
}

Correspondence

Tomohiko Tamura

tamura-tomohiko@nite.go.jp

\author{
Tomohiko Tamura, ${ }^{1}$ Yuumi Ishida, ${ }^{1}$ Misa Otoguro, ${ }^{1}$ Kazunori Hatano, ${ }^{1}$ \\ David Labeda, ${ }^{2}$ Neil P. Price ${ }^{3}$ and Ken-ichiro Suzuki ${ }^{1}$
}

\begin{abstract}
${ }^{1}$ NITE Biological Resource Center (NBRC), National Institute of Technology and Evaluation, 2-5-8 Kazusakamatari, Kisarazu, Chiba 292-0818, Japan

${ }^{2}$ Microbial Genomics and Bioprocessing Research Unit, National Center for Agricultural Utilization Research, Agricultural Research Service, US Department of Agriculture, Peoria, IL 61604, USA

${ }^{3}$ Bioproducts and Biocatalysis Research Unit, National Center for Agricultural Utilization Research, Agricultural Research Service, US Department of Agriculture, Peoria, IL 61604, USA
\end{abstract}

\begin{abstract}
Previous studies have proposed that Streptomyces caeruleus is an earlier heterotypic synonym for Streptomyces niveus and Streptomyces spheroides. In this study, phylogenetic analysis of the almost complete 16S rRNA gene sequences of the Streptomyces caeruleus type strains NBRC $13344^{\top}$, JCM $4014^{\top}$ and NRRL B-2194 ${ }^{\top}$ revealed that $S$. caeruleus was closely related to Actinoalloteichus cyanogriseus and not to $S$. niveus, S. spheroides or any other species of the genus Streptomyces. Moreover, the diagnostic cell-wall diamino acid was found to be meso-diaminopimelic acid in $S$. caeruleus and DNA-DNA hybridization studies revealed that $S$. caeruleus NBRC $13344^{\top}$ was a member of the same species as $A$. cyanogriseus NBRC $14455^{\top}$. Based on these chemotaxonomic and phylogenetic data, it is proposed that Streptomyces caeruleus (Baldacci 1944) Pridham et al. 1958 be reclassified as a heterotypic synonym of Actinalloteichus cyanogriseus Tamura et al. 2000. Furthermore, based on phylogenetic, morphological and MALDI-TOF MS analyses, it is proposed that the species Streptomyces laceyi Manfio et al. 2004 and Streptomyces spheroides Wallick et al. 1956 are reclassified as later heterotypic synonyms of Streptomyces niveus Smith et al. 1956.
\end{abstract}

Streptomyces caeruleus was first described by Baldacci (1944) as 'Actinomyces caeruleus' and then transferred to the genus Streptomyces by Pridham et al. (1958). In 2002, Lanoot et al. (2002) classified S. caeruleus as an earlier heterotypic synonym for both Streptomyces niveus (Smith et al., 1956) and Streptomyces spheroides (Harris et al., 1956) based on SDS-PAGE patterns of the whole-cell proteins and DNA-DNA relatedness. The International

Abbreviations: $\mathrm{A}_{2} \mathrm{pm}$, diaminopimelic acid; MALDI-TOF, matrix-assisted laser desorption/ionization time-of-flight; MS, mass spectroscopy.

The GenBank/EMBL/DDBJ accession numbers for the $16 \mathrm{~S}$ rRNA gene sequences of Streptomyces caeruleus NBRC $13344^{\top}$ and Streptomyces caeruleus NRRL B-2194 ${ }^{\top}$ are AB184345 and EF178675, respectively.

A supplementary figure showing the MALDI-TOF mass spectra of Streptomyces niveus NRRL $2466^{\top}$, Streptomyces spheroides NRRL $2449^{\top}$ and Streptomyces laceyi NRRL B-24638 ${ }^{\top}$ mycelium grown on glucose-proline novobiocin production medium is available with the online version of this paper.
Streptomyces Project (ISP) studied Streptomyces caeruleus ISP $5103^{\mathrm{T}}$ (Shirling \& Gottlieb, 1972), S. niveus ISP $5088^{\mathrm{T}}$ (Shirling \& Gottlieb, 1968a) and S. spheroides ISP $5292^{\mathrm{T}}$ (Shirling \& Gottlieb, 1968b) and reported on their morphological features and physiological characteristics. S. caeruleus ISP $5103^{\mathrm{T}}$ was observed to develop a flexuous (rectiflexibles) spore chain and to produce a distinct blackish-blue to very dark greyish-purple pigment, while S. niveus ISP $5088^{\mathrm{T}}$ and S. spheroides ISP $5292^{\mathrm{T}}$ were observed to develop spiral spore chains and produce no distinctive pigments.

Our preliminary examination revealed that $S$. caeruleus NBRC $13344^{\mathrm{T}}$ possessed meso-diaminopimelic acid (meso$\mathrm{A}_{2} \mathrm{pm}$ ) as the diagnostic diaminoacid of the cell-wall peptidoglycan and not LL- $\mathrm{A}_{2} \mathrm{pm}$ and we therefore carefully examined the taxonomic position of $S$. caeruleus. Four strains designated as type strains of $S$. caeruleus were obtained from different culture collections, namely NBRC 
$13344^{\mathrm{T}}$, JCM $4014^{\mathrm{T}}$, NRRL B-2194 ${ }^{\mathrm{T}}$ and LMG $19399^{\mathrm{T}}$, and were used in this study. PCR amplification and sequencing of the 16S rRNA genes of the strains and phylogenetic analysis were performed as described previously (Tamura \& Hatano, 2001). The 16S rRNA gene sequence of $S$. caeruleus NBRC $13344^{\mathrm{T}}$ was in agreement with those of $S$. caeruleus strains JCM $4014^{\mathrm{T}}$ and NRRL B-2194 ${ }^{\mathrm{T}}$ but was not in agreement with the sequence of $S$. caeruleus $\mathrm{LMG}$ $19399^{\mathrm{T}}$. Phylogenetic analysis revealed that S. caeruleus NBRC $13344^{\mathrm{T}}$ was found in a monophyletic cluster with members of the genus Actinoalloteichus (data not shown) and was closely related to Actinoalloteichus cyanogriseus. In contrast, S. caeruleus LMG $19399^{\mathrm{T}}$ was closely related to $S$. niveus and S. spheroides as reported by Lanoot et al. (2002) (data not shown). The binary similarity values of the $16 \mathrm{~S}$ rRNA gene sequences of $S$. caeruleus NBRC $13344^{\mathrm{T}}$ were $100 \%$ to $A$. cyanogriseus NBRC $14455^{\mathrm{T}}, 99.6 \%$ to Actinoalloteichus spitiensis MTCC $6194^{\mathrm{T}}$ and $96.7 \%$ to Actinoalloteichus hymeniacidonis HPA177 ${ }^{\mathrm{T}}$. The diagnostic diamino acid of the cell-wall peptidoglycan of $S$. caeruleus NBRC $13344^{\mathrm{T}}$ was reconfirmed as meso- $\mathrm{A}_{2} \mathrm{pm}$ by TLC (Hasegawa et al., 1983). The microplate hybridization method developed by Ezaki et al. $(1988,1989)$ was applied to determine DNA-DNA relatedness. The DNA-DNA relatedness values between S. caeruleus NBRC $13344^{\mathrm{T}}$ and A. cyanogriseus NBRC $14455^{\mathrm{T}}$ were 87.7 and $88.1 \%$ and were less than $24 \%$ between $S$. caeruleus NBRC $13344^{\mathrm{T}}$ and A. spitiensis NBRC $102582^{\mathrm{T}}$.

S. caeruleus and A. cyanogriseus exhibited almost the same phenotypic features in that they developed flexuous spore chains and produced blackish coloured soluble pigments (Tamura et al., 2000). Strains NBRC $13344^{\mathrm{T}}$, JCM $4014^{\mathrm{T}}$ and NRRL B-2194 ${ }^{\mathrm{T}}$ are members of the species S. caeruleus since they exhibit the same characteristics reported by the ISP
(Shirling \& Gottlieb, 1972). Further, S. caeruleus DSM $40103^{\mathrm{T}}$ has also been found to belong to the genus Actinoalloteichus (R. M. Kroppenstedt, personal communication).

Based on the phylogenetic, chemotaxonomic and DNADNA relatedness data, strain NBRC $13344^{\mathrm{T}}$, a type strain of S. caeruleus, is conclusively identified as a strain of $A$. cyanogriseus. Therefore, we propose that Streptomyces caeruleus (Baldacci 1944) Pridham et al. 1958 should be considered as a synonym of Actinoalloteichus cyanogriseus Tamura et al. 2000.

The present data and the phenotypic characteristics reported by the ISP (Shirling \& Gottlieb, 1968a, b, 1972) do not support the hypothesis that $S$. niveus and S. spheroides are later synonyms of $S$. caeruleus as proposed by Lanoot et al. (2002). It is likely that strain LMG $19399^{\mathrm{T}}$ could have been replaced with a streptomycete during deposit or during the subsequent maintenance of the strain. The present study, however, does support the synonymous relationship between $S$. niveus and S. spheroides as suggested by Lanoot et al. (2002). In addition, it was observed that Streptomyces laceyi NBRC $100783^{\mathrm{T}}$ (Manfio et al., 2003) was very closely related phylogenetically to $S$. niveus and S. spheroides based on $16 \mathrm{~S}$ rRNA gene sequences. The 16S rRNA gene sequences of $S$. laceyi NBRC $100783^{\mathrm{T}}$ and S. spheroides NRRL $2449^{\mathrm{T}}$ exhibited $99.8 \%$ and $99.9 \%$ sequence similarity to $S$. niveus NRRL $2466^{\mathrm{T}}$, respectively, and $99.9 \%$ similarity to each other. Moreover, the morphological appearance of all of these strains on various agar growth media is identical. $S$. niveus NRRL $2466^{\mathrm{T}}$ and S. spheroides NRRL $2449^{\mathrm{T}}$ are both reported to produce the same secondary metabolite, the antibiotic novobiocin, and it was of interest to determine whether S. laceyi NRRL B-24638 $8^{\mathrm{T}}\left(=\mathrm{NBRC} 100783^{\mathrm{T}}\right)$ exhibited a similar biosynthetic profile.

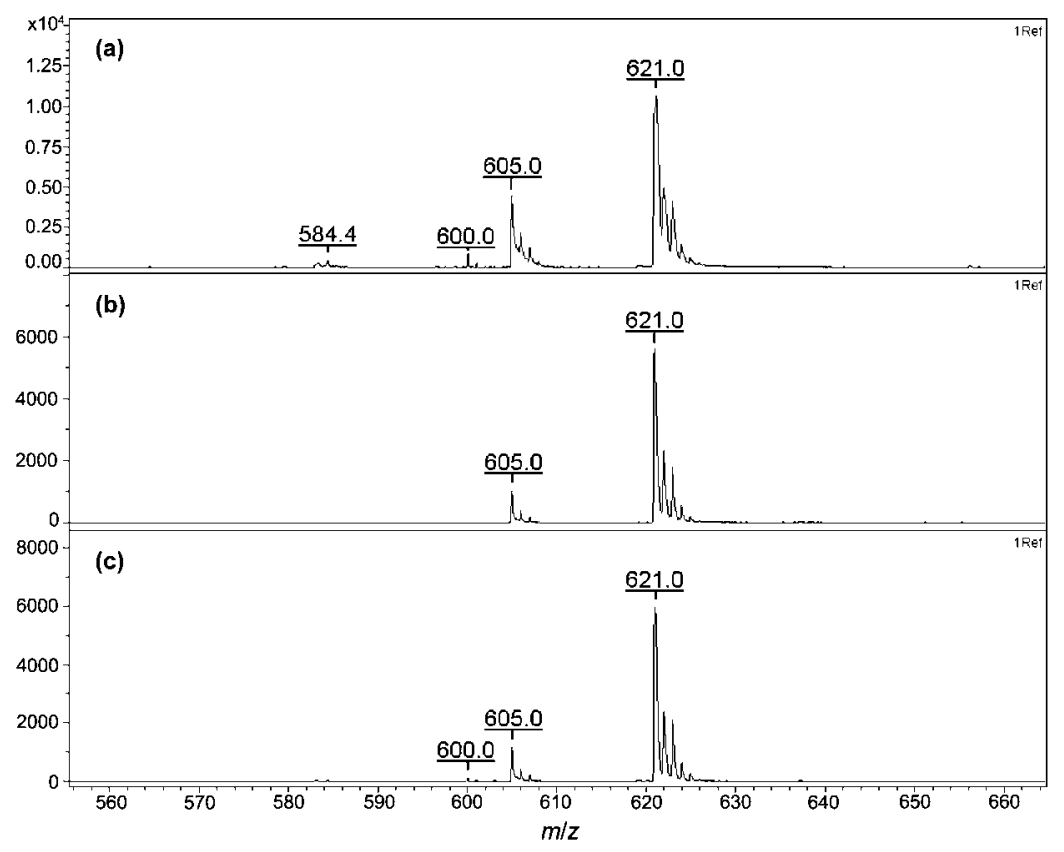

Fig. 1. MALDI-TOF mass spectra of (a) Streptomyces niveus NRRL $2466^{\top}$; (b) Streptomyces spheroides NRRL $2449^{\top}$, and (c) Streptomyces laceyi NRRL B-24638 ${ }^{\top}$ mycelium grown for 14 days on $\mathrm{N}$-Z-amine medium (DSM medium 554). 
All three strains were grown on $\mathrm{N}-\mathrm{Z}$-amine agar (DSMZ, 2001) and colonies were analysed by matrix-assisted laser desorption/ionization time-of-flight (MALDI-TOF) MS of intact cells using a Omniflex MALDI-TOF mass spectrometer (Bruker Daltonic) run in reflectron mode. The MALDI-TOF MS analysis of the three strains showed that these strains produced the same ion profiles (major ions $\mathrm{m} / z 605$ and $\mathrm{m} / \mathrm{z}$ 621; Fig. 1 and shown in more detail in Supplementary Figure S1, available in IJSEM Online), although none of these matched the mass for the novobiocin standard (data not shown), and can thus be considered as the same species.

The DNA-DNA relatedness values of $S$. niveus NBRC $12804^{\mathrm{T}}$ were 66 and $90 \%$ to S. spheroides NBRC $12917^{\mathrm{T}}$ and S. laceyi NBRC $100783^{\mathrm{T}}$, respectively. An investigation of the literature found that the species $S$. niveus Smith et al. 1956 was effectively published in February 1956 and should take precedence over S. spheroides Wallick et al. 1956 which seems to have appeared in print in May 1956. We therefore propose the following circumscription for Streptomyces niveus.

Streptomyces niveus Smith et al. 1956, type strain NRRL $2466^{\mathrm{T}}$ [=ATCC $19793^{\mathrm{T}}=$ CBS $545.68^{\mathrm{T}}=$ BCRC (formerly CCRC) $\quad 11514^{\mathrm{T}}=$ CCUG $\quad 11108^{\mathrm{T}}=$ DSM $\quad 40088^{\mathrm{T}}=$ IFM $1181^{\mathrm{T}}=\mathrm{IFO} \quad\left(\right.$ now NBRC) $12804^{\mathrm{T}}=\mathrm{IMET} \quad 43503^{\mathrm{T}}=\mathrm{JCM}$ $4251^{\mathrm{T}}=\mathrm{JCM} \quad 4599^{\mathrm{T}}=\mathrm{LMG} \quad 5980^{\mathrm{T}}=\mathrm{LMG} \quad 19395^{\mathrm{T}}=\mathrm{NCIMB}$ $9219^{\mathrm{T}}$, NRRL-ISP $5088^{\mathrm{T}}=$ RIA $1072^{\mathrm{T}}=$ UNIQEM $179^{\mathrm{T}}$ ], has the following later heterotypic synonyms: Streptomyces laceyi Manfio et al. 2003, type strain $\mathrm{C}^{2} 654^{\mathrm{T}}\left(=\mathrm{AS} 4.1832^{\mathrm{T}}=\mathrm{DSM}\right.$ $41788^{\mathrm{T}}=\mathrm{JCM} 12606^{\mathrm{T}}=$ NBRC $100783^{\mathrm{T}}=\mathrm{NCIMB} 13928^{\mathrm{T}}=$ NRRL B-24638 ${ }^{\mathrm{T}}$ ) and Streptomyces spheroides Wallick et al. 1956, type strain NRRL $2449^{\mathrm{T}}$ [=ATCC $23965^{\mathrm{T}}=\mathrm{CBS}$ $491.62^{\mathrm{T}}=$ CBS $948.68^{\mathrm{T}}=$ BCRC (formerly CCRC) $11559^{\mathrm{T}}=$ DSM $40292^{\mathrm{T}}=$ IFO (now NBRC) $12917^{\mathrm{T}}=\mathrm{JCM} 4252^{\mathrm{T}}=\mathrm{JCM}$ $4670^{\mathrm{T}}=$ LMG $19392^{\mathrm{T}}=$ NCIMB $11891^{\mathrm{T}}=$ NRRL-ISP $5292^{\mathrm{T}}=$ RIA $1200^{\mathrm{T}}=$ RIA $700^{\mathrm{T}}$ ].

\section{Acknowledgements}

The authors thank Drs T. Kudo, JCM, and R. M. Kroppenstedt, DSMZ, for their valuable contributions of data and discussion. Names are necessary to report factually on available data; however, the USDA neither guarantees nor warrants the standard of the product, and the use of the name by USDA implies no approval of the product to the exclusion of others that may also be suitable.

\section{References}

Baldacci, E. (1944). Contributo alla sistematica degli attinomiceti: XXVI. Actinomyces madurae; Proactinomyces ruber; Proactinomyces pseudomadurae, Proactinomyces polychromogenus; Actinomyces violaceus; Actinomyces caeruleus; con un elenco alfabetico delle specie e delle varieta finora studiate. Atti Ist Botan Universita Laboratorio Crittogamico di Pavia Series 5 3, 139-193.

DSMZ (2001). Catalogue of Strains. Braunschweig: Deutsche Sammlung von Mikroorganismen und Zellkulturen.

Ezaki, T., Hashimoto, Y., Takeuchi, N., Yamamoto, H., Liu, S.-L., Miura, H., Matsui, K. \& Yabuuchi, E. (1988). Simple genetic identification method of viridans group streptococci by colorimetric dot hybridization and quantitative fluorometric hybridization in microdilution wells. J Clin Microbiol 26, 1708-1713.

Ezaki, T., Hashimoto, Y. \& Yabuuchi, E. (1989). Fluorometric deoxyribonucleic acid-deoxyribonucleic acid hybridization in microdilution wells as an alternative to membrane filter hybridization in which radioisotopes are used to determine genetic relatedness among bacterial strains. Int J Syst Bacteriol 39, 224-229.

Harris, D. A., Reagan, M. A., Ruger, M., Wallick, H. \& Woodruff, H. B. (1956). Discovery and antimicrobial properties of cathomycin, a new antibiotic produced by Streptomyces spheroides n. sp. Antibiot Annu 1955-56, 909-917.

Hasegawa, T., Takizawa, M. \& Tanida, S. (1983). A rapid analysis for chemical grouping of aerobic actinomycetes. J Gen Appl Microbiol 29, 319-322.

Lanoot, B., Vancanneyt, M., Cleenwerck, I., Wang, L., Li, W., Liu, Z. \& Swings, J. (2002). The search for synonyms among streptomycetes by using SDS-PAGE of whole-cell proteins. Emendation of the species Streptomyces aurantiacus, Streptomyces cacaoi subsp. cacaoi, Streptomyces caeruleus and Streptomyces violaceus. Int J Syst Evol Microbiol 52, 823-829.

Manfio, G. P., Atalan, E., Zakrzewska-Czerwinska, J., Mordarski, M., Rodriguez, C., Collins, M. D. \& Goodfellow, M. (2003). Classification of novel soil streptomycetes as Streptomyces aureus sp. nov., Streptomyces laceyi sp. nov. and Streptomyces sanglieri sp. nov. Antonie van Leeuwenhoek 83, 245-255.

Pridham, T. G., Hesseltine, C. W. \& Benedict, R. G. (1958). A guide for the classification of streptomycetes according to selected groups; placement of strains in morphological sections. Appl Microbiol 6, 52-79.

Shirling, E. B. \& Gottlieb, D. (1968a). Cooperative description of type cultures of Streptomyces. II. Species descriptions from first study. Int $J$ Syst Bacteriol 18, 69-189.

Shirling, E. B. \& Gottlieb, D. (1968b). Cooperative description of type cultures of Streptomyces. III. Additional species descriptions from first and second studies. Int J Syst Bacteriol 18, 279-392.

Shirling, E. B. \& Gottlieb, D. (1972). Cooperative description of type strains of Streptomyces. V. Additional descriptions. Int J Syst Bacteriol 22, 265-394.

Smith, C. G., Dietz, A., Sokolski, W. T. \& Savage, G. M. (1956). Streptonivicin, a new antibiotic. I. Discovery and biologic studies. Antibiot Chemother 6, 135-142.

Tamura, T. \& Hatano, K. (2001). Phylogenetic analysis of the genus Actinoplanes and transfer of Actinoplanes minutisporangius Ruan et al. 1986 and 'Actinoplanes aurantiacus' to Cryptosporangium minutisporangium comb. nov. and Cryptosporangium aurantiacum sp. nov. Int J Syst Evol Microbiol 51, 2119-2125.

Tamura, T., Liu, Z., Zhang, Y. \& Hatano, K. (2000). Actinoalloteichus cyanogriseus gen. nov., sp. nov. Int J Syst Evol Microbiol 50, 1435-1440. 